\title{
Numerical simulation of the effects on residual chlorine water discharge from LNG on the ocean water environment ${ }^{*}$
}

\author{
Yi Zhang ${ }^{1}$, Ming-Yuan Sun ${ }^{1,2}$ and Long-Xi Han ${ }^{1,3}$ \\ ${ }^{1}$ College of Environment, Hohai University, \\ Nanjing, 210098, China \\ ${ }^{2}$ Ocean and Fisheries Bureau of Jiangsu Province \\ Nanjing, 210098, China \\ ${ }^{3}$ Key Laboratory of Integrated Regulation and Resource \\ Development on Shallow Lake of Ministry of Education, \\ Nanjing, 210098, China \\ E-mail:hhuzhangyi@126.com
}

\begin{abstract}
In order to research the distribution of residual chlorine of LNG drainage in the ocean, further to formulate reasonable wastewater marine disposal scheme and provide scientific support to the protection of environment. According to the tidal current characteristics of the drainage and receiving waters in the LNG project and the design of the typical hydrological conditions of different seasons, a 2D hydrodynamic model was used to simulate the tidal current field of waters receiving residual chlorine in cold water discharge in the Radial sand ridge group of shallow sea area of Jiangsu maritime space. And as the hydrodynamic conditions in the simulation of the cold water mobility and transfer of two dimensional model of the transport and diffusion for the residual chlorine was established to predict the receiving waters residual chlorine concentration distribution and analyze its environmental impact in considering the residual chlorine in water body of attenuation effect at the same time. Finally, the scope of influence caused by the chlorine water drainage in the chlorine water's sphere was analyzed quantitatively according to the chronic toxicity threshold line of residual chlorine. Results show that the residual chlorine in LNG cold drainage less affected in the water environment.
\end{abstract}

Keywords: LNG; Offshore area; Residual Chlorine; Numerical Simulation.

\section{Introduction}

Ocean is an important part of the global life support system and a natural resource for human survival. The vast waters and good hydrodynamic conditions becomes an ideal place for acceptance and purification of tail water pollutants, and the marine disposal of urban sewage has become one of the important choices of coastal cities and areas.

\footnotetext{
* Work partially supported by grant of the special funds from Ocean and Fisheries Bureau of Jiangsu Province.
} 
With the aggravation of the world energy crisis, the development of new energy such as liquid natural gas has become an important part of the sustainable development of China's economy in recent years. The implementation of such projects in a certain extent promote to LNG as the representative of the clean energy applications so as to adjust the energy structure, improvement of regional energy consumption on the environment pollution, and improve the regional development of environmental carrying capacity[1].But it will also create a new marine water pollution by residual chlorine water at the same time.

In order to remove the algae microorganism attached to the pipeline during the production of LNG receiving station, there's need to add the circulating water amount of chlorine, so that the discharged water contains chlorine. Toxic effects of chlorine on aquatic organisms is relatively large. When the cooling water containing chlorine discharged into nearby waters, it will affect the ecological environment of water. Brook found that when chlorine wastewater discharged into the ocean, it would inhibit phytoplankton photosynthesis and respiration by comparing the effects of temperature and water drainage on the phytoplankton[2].Ceng Jiangning carried out the analysis on the influence of residual chlorine on plankton, shellfish and fish, and draw the conclusion that the impact of chlorine in marine fish was more obvious[3].

Under this background, the research on residual chlorine water discharge from LNG is especially important. TursunajMuiti analyzed the impact of power plant cooling water containing chlorine discharged into the Yangtze River on the water environment by two dimensional numerical simulation ${ }^{[4]}$; Zhang Yan simulated the sea area near the Jiaozhou Bay power plant by using the finite element method, and predicted the concentration distribution and influence of residual chlorine in water[5]. Xu Zhaoli analyzed the effect of chlorine containing wastewater on marine organisms from fire (nuclear) power plant emissions and LNG receiving station[6]. Bi Wenbin predicted cooling water in Jiaonan power plant in the ocean after discharge residual chlorine concentration distribution by numerical simulation[7].But the above study have not forecast the maximum possible influence range of chlorine.

\section{Hydrodynamic Simulation}

A 2-D hydrodynamic model was used to simulate the tidal current field in the shallow sea area of the radial sand ridges in the Jiangsu coast (see Figure 1). The range from south to north is $31^{\circ} 58^{\prime} \mathrm{N}-33^{\circ} 14^{\prime} \mathrm{N}$, the distance is $152 \mathrm{~km}$. The range from east to west is $120^{\circ} 46^{\prime} \mathrm{E}-121^{\circ} 51^{\prime} \mathrm{E}$, width across $102 \mathrm{~km}$. This method is mature, many literatures have discussed[8-9]. 


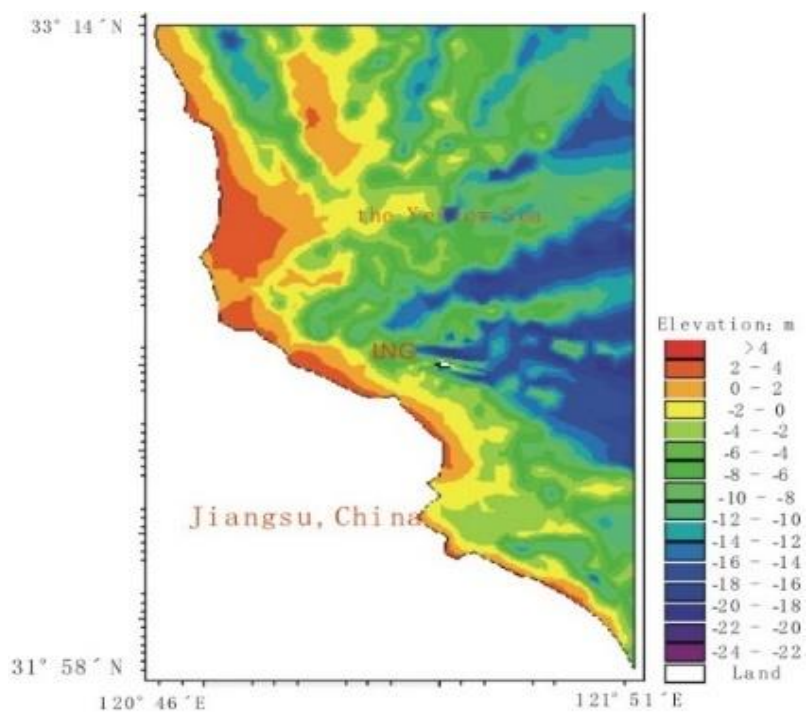

Fig. 1. Sea area terrain around $\mathrm{LNG}$ project.

Different combination of sequence boundary points on the tidal level process were taken as the input condition of hydrology. The TPXO model was used to obtain the boundary of tidal level process.

\subsection{Flow Field Simulation in the area}

Considering the seasonal difference of tidal current in the sea area, the different flow field directly affects the migration and diffusion of pollutants, so as to influence the prediction results. Select summer and winter two seasons as a typical period of time to simulate the hydrodynamic conditions in the region. Flow field distribution of summer and winter are shown in Figure 2 and 3.

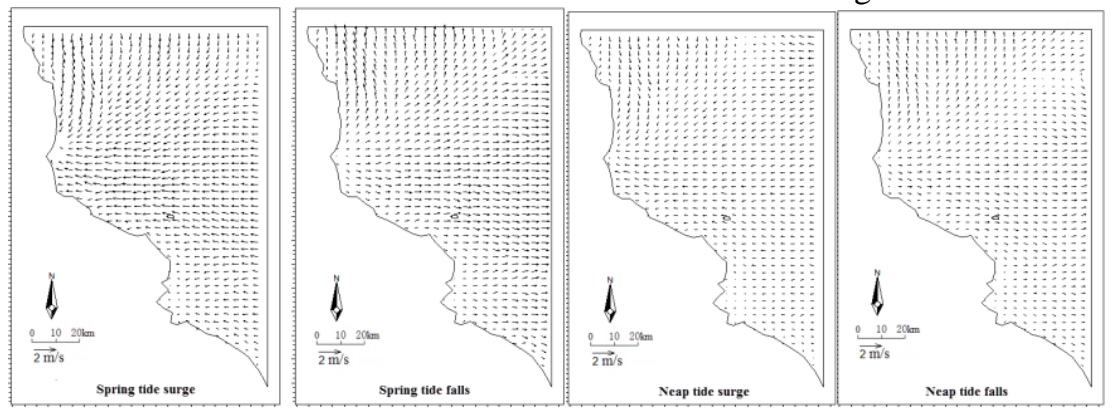

Fig. 2. Summer flow field map. 


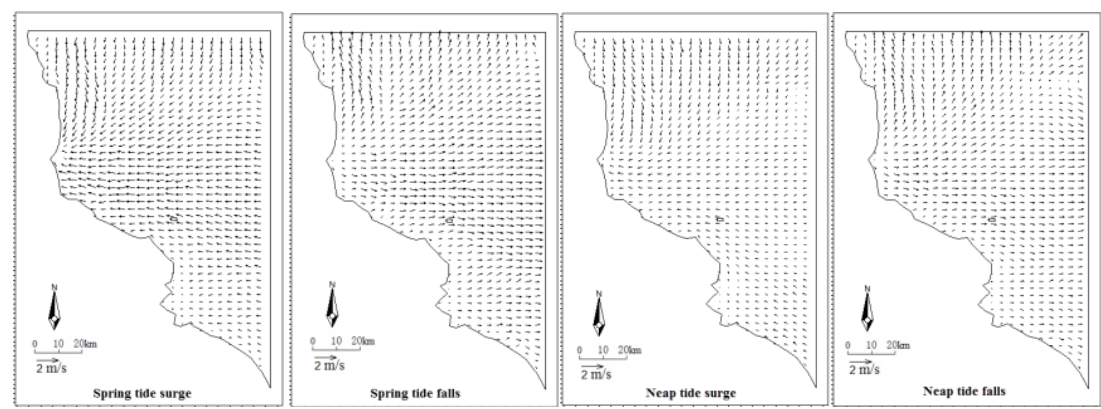

Fig. 3. Winter flow field map.

\subsection{Hydrodynamic characteristics analysis}

The results show that, the main trend of the flow was similar to NE-SW during the flood tide, which is perpendicular to the coastline, and when the ebb tide is opposite. The regional flow rate is generally larger, the flow rate of the summer was significantly greater than that in winter, and the water velocity of the flood tide is higher than the ebb tide.

In the area near the shore, affected by the shoreline and topography, tidal current flows paralleled to the shore, and the local water flow is different from the main tidal current due to the change of coastline. Overall, during the flood tide, the trend in the northern coast area is southward, the trend in southern coast area is in the direction of the northeast, and when the ebb tide it is opposite. The velocity of water flow in the near shore water is less than the velocity of the water.

The drainage outlet is located on the artificial island which has a certain distance from the shore boundary, so the velocity and direction is less affected by the shore, and the water flow condition is relatively simple. Results shows that, the flow direction is approximately west at the sewage outfall during the flood tide, and the flow direction is east during the ebb tide. The average velocity at the outfall were $0.253 \mathrm{~m} / \mathrm{sin}$ spring tide and $0.182 \mathrm{~m} / \mathrm{s}$ in neap tide.

\section{Chlorine Distribution Simulation}

\subsection{Two dimensional convection diffusion model}

The residual chlorine in non-uniform flow in 2D convection diffusion equation can be expressed as Eq. (1).

$$
\frac{\partial \rho}{\partial \mathrm{t}}+\mathrm{u} \frac{\partial \rho}{\partial \mathrm{x}}+\mathrm{v} \frac{\partial \rho}{\partial \mathrm{y}}=\frac{\partial}{\partial \mathrm{x}}\left(\mathrm{E}_{\mathrm{x}} \frac{\partial \rho}{\partial \mathrm{x}}\right)+\frac{\partial}{\partial \mathrm{y}}\left(\mathrm{E}_{\mathrm{y}} \frac{\partial \rho}{\partial \mathrm{y}}\right)-\mathrm{K} \rho+\mathrm{S}
$$


Form in: $\rho$-concentration of chlorine, $\mathrm{t}$-time, $\mathrm{x}, \mathrm{y}$-distance, $u \& v-$ vertical and horizontal vertical average velocity, $\mathrm{E}_{\mathrm{x}} \& \mathrm{E}_{\mathrm{y}}$ - diffusion coefficient, $\mathrm{K}$-attenuation coefficient, $\mathrm{S}$-pollutant source concentration.

\subsection{Definite solution condition}

(1) Boundary condition

(a) Shore boundary

$$
\frac{\partial \theta}{\partial n}=0
$$

Form in: $\bar{n}$ is boundary normal.

(b) Open boundary

Low tide: $\frac{\partial \theta}{\partial t}+\bar{u} \bullet-\frac{\partial \theta}{\partial n}=0$

High tide: $\theta=0$

(2) Initial condition

All initial conditions are 0 .

\subsection{Determination of parameters and source strength}

\subsubsection{Diffusion coefficient}

The velocity field in natural sea area is generally not uniform. Diffusion coefficient is an important parameter which is not easy to be determined, and it often has the property of empirical coefficient. The diffusion coefficient formula used in this paper is as follows:

$$
\begin{aligned}
& \mathrm{E}_{\mathrm{x}}=\alpha_{\mathrm{x}} h \mathrm{u}_{*} \\
& \mathrm{E}_{\mathrm{y}}=\alpha_{\mathrm{y}} \mathrm{hu} \mathrm{u}_{*}
\end{aligned}
$$

Form in: $\mathrm{h}$-water depth, $u_{*}$-frictional velocity, $\alpha_{x} \& \alpha_{y}$-empirical coefficient, taken as 4.0 and 0.5 .

\subsubsection{Attenuation coefficient of residual chlorine}

Usually the residual chlorine decay hypothesis is a first-order reaction, and its model is as follows:

$$
\frac{\mathrm{dC}}{\mathrm{dt}}=-\mathrm{KC}
$$

Form in: $\mathrm{C}$ - concentration of chlorine, $\mathrm{K}$ - attenuation coefficient. 
Refer to relevant experiments[10-11], the half-life of residual chlorine is selected as $1 \mathrm{~h}$ in this paper, and according to the first-order decay model of residual chlorine, the calculation results of residual chlorine attenuation coefficient is 0.69 .

\subsubsection{Pollutant source concentration}

According to the data, the drainage of the $\mathrm{LNG}$ receiving station was $10.35 \mathrm{~m}^{3} / \mathrm{s}$, and the residual chlorine concentration was $0.0002 \mathrm{~kg} / \mathrm{m}^{3}$.

\subsection{Forecast result}

In this paper, we used the above model and its solution, simulated the full tidal cycle under two typical hydrological conditions considering the most adverse effects, and predicted the mass concentration of residual chlorine.

The residual chlorine concentration increment isoclines near the drains in winter and summer are shown in Figure 4 and 5, and the space distribution distance are shown in Table 1 and 2.

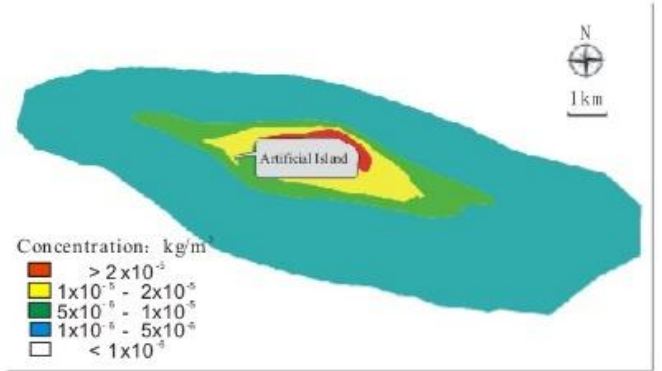

Fig. 4. Residual chlorine concentration increment is line in winter $\left(\mathrm{kg} / \mathrm{m}^{3}\right)$

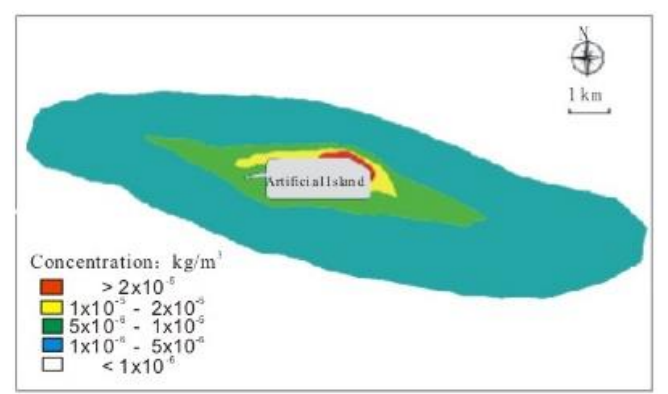

Fig. 5. Residual chlorine concentration increment is line in summer $(\mathrm{kg} / \mathrm{m} 3)$ 
Table 1. The space distribution distance of residual chlorine concentration increment in winter

\begin{tabular}{cccc}
\hline Term & \multicolumn{3}{c}{ Residual chlorine concentration } \\
& $\geq 2 \times 10^{-5} \mathrm{~kg} / \mathrm{m}^{3}$ & $\geq 1 \times 10^{-5} \mathrm{~kg} / \mathrm{m}^{3}$ & $\geq 5 \times 10^{-6} \mathrm{~kg} / \mathrm{m}^{3}$ \\
\hline Total Lenth $(\mathrm{m})$ & 2900 & 6200 & 9700 \\
Max Width $(\mathrm{m})$ & 500 & 1300 & 1900 \\
Area $\left(\mathrm{km}^{2}\right)$ & 0.752 & 3.41 & 10.48 \\
\hline
\end{tabular}

Table 2. The space distribution distance of residual chlorine concentration increment in summer

\begin{tabular}{cccc}
\hline Term & \multicolumn{3}{c}{ Residual chlorine concentration } \\
& $\geq 2 \times 10^{-5} \mathrm{~kg} / \mathrm{m}^{3}$ & $\geq 1 \times 10^{-5} \mathrm{~kg} / \mathrm{m}^{3}$ & $\geq 5 \times 10^{-6} \mathrm{~kg} / \mathrm{m}^{3}$ \\
\hline Total Lenth $(\mathrm{m})$ & 1550 & 4400 & 8800 \\
Max Width $(\mathrm{m})$ & 180 & 580 & 1800 \\
Area $\left(\mathrm{km}^{2}\right)$ & 0.273 & 1.58 & 7.84 \\
\hline
\end{tabular}

\section{Study on the Effect of Chlorine on Water Environment}

Based on the predicted results, the contaminants formed an extension of the strip area around the drain port under the action of tidal current. And due to the local influence of artificial island, the pollutant zone extended along the direction of the shore boundary attaching to the bank near the drains. In summer, the velocity of tidal current field is larger, and the diffusion condition is better, so the pollution belt with the same pollution load is covered by a small area. In winter, the velocity of tidal current field is smaller, and is not conducive to the spread of pollutants, so the pollution belt with the same pollution load covers a large area. The typical pollution load values are represented by the size of the pollution belt as follows:

(1) In summer, the increment value of maximum residual chlorine concentration greater than $0.02 \mathrm{mg} / \mathrm{L}$ is approximated to a band range of the length of $1550 \mathrm{~m}$, width of $180 \mathrm{~m}$, and the area of $0.273 \mathrm{~km}^{2}$. Which greater than $0.01 \mathrm{mg} / \mathrm{L}$ is approximated to the length of $4400 \mathrm{~m}$, width of $580 \mathrm{~m}$, and the area of $1.58 \mathrm{~km}^{2}$.

(2) In winter, the increment value of maximum residual chlorine concentration greater than $0.02 \mathrm{mg} / \mathrm{L}$ was approximated to a band range of the length of $2900 \mathrm{~m}$, width of $500 \mathrm{~m}$, and the area of $0.752 \mathrm{~km}^{2}$. Which greater than $0.01 \mathrm{mg} / \mathrm{L}$ is approximated to the length of $6200 \mathrm{~m}$, width of $1300 \mathrm{~m}$, and the area of $3.41 \mathrm{~km}^{2}$.

In summary, the distribution of the pollutants in drainage is small, and pollution near the drain is a little more serious. In a full tidal current, the average value of the pollution load in the water is much lower than the maximum value, because the equivalent line is selected as the maximum value at different time, which appeared only in an instant. 
At present, China has not yet formulated chlorine concentration standard safety on aquatic organisms, so in this paper the research results of foreign scholars had been carried out. Matlice and Zitlel derived marine residual chronic toxicity threshold line of universal significance[12], which value was $2 \times 10^{-5}$ $\mathrm{kg} / \mathrm{m}^{3}$. That is to say, when the concentration of residual chlorine is less than $2 \times 10^{-5} \mathrm{~kg} / \mathrm{m}^{3}$, it will not have toxic effects on aquatic organisms no matter how long it takes. From the prediction results of this paper, in the drainage of the LNG project, the impact of chlorine on the water environment of coastal waters was relatively small.

\section{Conclusions and Prospects}

\subsection{Conclusions}

(1) Simulation results show that, the contaminants in the low chlorine water formed an extension of the strip area around the drain port under the action of tidal current. Due to the local influence of artificial island, the pollutant zone extended along the direction of the shore boundary attaching to the river bank near the drains. In the summer hydrological conditions, the velocity of tidal current field is larger, and the diffusion condition is better, so the pollution belt with the same pollution load is covered by a small area. And in winter, the velocity is smaller, and is not conducive to the spread of pollutants, the pollution belt with the same pollution load covers a large area.

(2) According to the chronic toxicity of marine biological chlorine threshold line $\left(2 \times 10^{-5} \mathrm{~kg} / \mathrm{m}^{3}\right)$, the pollution zone which may have an impact on the marine life was obtained: in winter, the pollution zone was approximated to a band range of the length of $2900 \mathrm{~m}$, width of $500 \mathrm{~m}$, and the area of $0.752 \mathrm{~km}^{2}$, and in summer, the zone was approximated to the length of $1550 \mathrm{~m}$, width of $180 \mathrm{~m}$, and the area of $0.273 \mathrm{~km}^{2}$.

(3) The predicted result is the maximum increment of pollutant concentration in adverse hydrological condition, that is, the concentration of pollutant was selected as the maximum concentration at different time in the whole simulation period. This maximum occurs only in an instant. Therefore, in a full tidal current, the average value of the pollution load in the water was much lower than the maximum value. The simulation results also show that the maximum increment of the pollutant concentration in the project area is also relatively small, therefore the low temperature chlorine drainage of the project is relatively small impact on the water environment nearby. 


\subsection{Prospects}

(1) This paper was based on the numerical simulation of 2D model. 3D model is more appropriate to reflect the actual flow of water. The future research may consider using to simulate the water transport characteristics and pollutants.

(2) The influence of residual current and wave was not considered in this paper, so the simulation of the water flow couldn't show the nonlinear characteristics of the actual coastal water. These factors could be considered in further research.

(3) This paper didn't consider the impact on the chlorine diffusion migration caused by the density flow due to the temperature difference after the low temperature water entered the natural body. Further discussion on this aspect can be further discussed in the following studies.

\section{References}

1. Wang Huabei. Reserch in Development and Application of China's LNG Industry[D], Daqing Petroleum Institute, 2009.(In Chinese)

2. Brook A J Baker A L. Chlorination at power plant: impact on phytoplankton productivity[J]. Science, 1972, 178: 1414-1415.

3. Zeng Jiangning, Chen Quanzhen, Zheng Ping, et al., Advanced in effect of residual chlorine on hydrobios[J], Acta Ecologica Sinica, 2005, (10):27172724.(In Chinese)

4. Muyiti Tuerxunayi, Han Long-xi, Jin Jian, Numerical simulation of the effects of residual chlorine in cooling water discharge from a power plant on the water environment[J], Journal of Hohai University(Natural Sciences), 2008, (04):475-478. (In Chinese)

5. Zhang Yan, Sun Yinglan, Numerical prediction for transport and diffusion of residual chlorine in cooling water drainage of the power plant[J].Marine Sciences, 2007, (02):5-8. (In Chinese)

6. Xu Zhaoli, Li Ming, Zhang Guangyu, et al. Principle of environmental protection in engineering design for intake and waterspout of power station[J].Marine Environmental Sciences, 2011,(02):234-238. (In Chinese)

7. BiWenbin, SunYinglan, Numerical prediction for transport and diffusion and estimation of fishery losses of residual chlorine[J].Transactions of Oceanology and Limnology, 2009, (01):57-60.(In Chinese)

8. Zhang Xueqing, Sun Yinglan, Numerical Simulation of 3D Tidal Current in the Offshore Area of Jiaonan [J]. Periodical of Ocean University of China, 2005, (04): 579-582.(In Chinese) 
9. Wang Xuechang, Sun Changqing, Sun Yinglan, et al. Study on impact of Jiaozhou Bay sea-filling on hydrodynamic environment[J].Marine EnviromentalSciences,2000,(03):55-59. (In Chinese)

10. Liu Lanfen, Hao Hong, Lu Guangsi, Experiment study on attenuation law of residual chlorine in cooling water discharged from thermal power plants[J].Journal of Hydraulic Engineering,2004,(05):94-98. (In Chinese)

11. Zhang Sui, Huang Honghui, Chen Haoru, et al. Environmental effects of residual chlorine discharged from Daya Bay nuclear power station on the adjacent waters[J].Marine EnviromentalSciences,2000,(02):14-18.(In Chinese)

12. Matlice J Sand Zittlel H E. Site-specific evaluation of power plant Chlorination,(Journal Water Pollution Control Federation, 1976), 44(10):2284-2308. 